\title{
The importance of user controlled research on coercion Jasna Russo
}

Address: Für alle Fälle, e.V., Auguststr.71, 10117 Berlin, Germany

from WPA Thematic Conference. Coercive Treatment in Psychiatry: A Comprehensive Review

Dresden, Germany. 6-8 June 2007

Published: 19 December 2007

BMC Psychiatry 2007, 7(Suppl I):S59 doi:10.1 186/I47I-244X-7-SI-S59

This abstract is available from: http://www.biomedcentral.com/I47I-244X/7/SI/S59

(c) 2007 Russo; licensee BioMed Central Ltd.

Coercion in psychiatry is one of the main topics in user/ survivor movement worldwide. At the same time user controlled research in this field is almost non existent $[1,2]$. The reasons for this situation will be analyzed, the need for research on coercion and the obstacles that research done by users/survivors faces. The presentation will also outline possible methodologies, their advantages and their potential.

\section{References}

I. Faulkner A: The Ethics of Survivor Research - Guidelines for the Ethical Conduct of Research Carried out by Mental Health Service Users and Survivors Bristol, UK: Joseph Rowntree Foundation; 2004.

2. Turner M, Beresford P: User Controlled Research - Its Meanings and Potential London, UK: Shaping Our Lives and the Center for Citizen Participation, Brunel University; 2005. 